\title{
Chemical Composition of Taxus baccata L. Leaves and Male Cones Water: Methanol Extracts
}

\author{
Younes Shirmohammadli ${ }^{1}$, Seyyed Khalil Hosseinihashemi ${ }^{2 *}$, Abbas Jalaligoldeh ${ }^{3}$, Davood Efhamisisi ${ }^{4}$, \\ Seyed Hashem Mousavinezhad ${ }^{5}$, Amir Lashgari ${ }^{2}$
}

\author{
${ }^{1}$ Department of Civil and Environmental Engineering, Faculty of Engineering, The University of Auckland, New \\ Zealand. \\ 2 Department of Wood Science and Paper Technology, Karaj Branch, Islamic Azad University, Karaj, Iran \\ ${ }^{3}$ Department of Horticulture Sciences, Karaj Branch, Islamic Azad University, Karaj, Iran \\ ${ }^{4}$ Department of Wood and Paper Science and Technology, Faculty of Natural Resources, University of Tehran, \\ Karaj, Iran \\ ${ }^{5}$ Department of Forestry and Forest Ecology, Gorgan University of Agricultural Sciences and Natural Resources, \\ Gorgan, Iran \\ *hashemi@kiau.ac.ir \\ *Orcid No: 0000-0001-6236-0376
}

Received: 14 February 2020

Accepted: 14 September 2020

DOI: $10.18466 /$ cbayarfbe. 689482

\begin{abstract}
The yew tree (Taxus baccata) is an ancient species in the world that has both toxic and medicinal properties. Identifying the chemical components of different parts of this tree can be useful in the better understanding of the toxicity and medicinal effect of this plant. Therefore, the chemical composition of water: methanol extracts of T. baccata L. leaf and male cones obtained from endemic species of Iran were characterized using GC-MS analysis. Twenty two components were identified for leaves including oleic acid (20.87\%) and octadeca-9,12-dien-1-ol (17.77\%) as the most abundant components, and seventeen components were identified for male cones which were 3-O-methyl-d-glucose $(64.00 \%)$ and oleic acid $(13.32 \%)$ as the most abundant components. Furthermore, the potential applications of some of the characterized components are discussed into the depths.
\end{abstract}

Keywords: Taxus baccata leaves and male cones, water: methanol extract, GC-MS, chemical composition, 3-O-methyl-d-glucose.

\section{Introduction}

Yew (Taxus baccata), is a coniferous tree or shrub which reaches a height of 15 meters [1] and widely distributed in western, central and southern Europe, northwest Africa, southwest Asia, and northern Iran [24]. Yew has evergreen leaves consist of several short, narrow needles with a length of 1 to $2 \mathrm{~cm}$ and a width of 1 to $2 \mathrm{~mm}$ [5]. Furthermore, the male cones appear in the axils of the leaves; which are globose with 6-14 peltate scales, each with 4-8 pollen sacs [6].

There have been many observations of poisoning due to the ingestion of yew in animals and humans, and the identification of its constituents can help to a better understanding the toxicity and poisoning of this species $[7,8]$. On the other hand, various medical characteristics have been liked to yew and embracing new therapeutic compounds for the treatment of diseases and a tendency to increase the use of natural compounds, the identification of yew compounds can open a new window for human needs [9]. Many studies have been focused on the beneficial component extraction from the bark of the T. baccata which dries and destroys this slow-growing and low- population species. One of the means to protect this species is to use the re-growing parts of the plant and also finding and applying the component extraction method is of vital importance [10]. Plant species, habitat environment, and height and the method used to extract the components are effective factors in determining the type and amount of components [11, 12]. This study aimed to extract the leaf and male cones components of yew and identify its constituents to provide a better perspective about the T. baccata growing in Iran.

\section{Materials and Methods \\ 2.1 Plant Material}

Fresh branches containing green needle leaves and male cones of the fallen yew tree due to wind or landslides were collected from Afratakhteh forests in Golestan 
province, Iran, in October 2017. The plant material with a voucher specimen number 4657 was deposited to the Herbarium in the college of Agricultural and Natural Resources, Karaj Branch, Islamic Azad University, Karaj, Iran. The plant male cones were isolated from the end of leaves of the plant and they were both washed briefly with distilled water to remove dust and then dried at room temperature. They were kept in the refrigerator at $4{ }^{\circ} \mathrm{C}$ until extraction.

\subsection{Extraction}

All solvents used for extraction were supplied from Merck Company, Darmstadt, Germany. The water: methanol extracts of leaves and male cones were extracted sequentially in three steps. In the first step, fresh leaves and male cones samples (approximately 10 $\mathrm{g}$ of each) were separated and soaked in $150 \mathrm{~mL}$ of $n$ hexane in a $250-\mathrm{mL}$ Erlenmeyer flask. The extraction was performed using the shaker technique for $3 \mathrm{~h}$ at 4.5 rpm speed. The extracts were filtered and the residue was eluted with $50 \mathrm{~mL}$ of $n$-hexane again. In the second step, the residue was processed similarly with the same amount of chloroform for the same period in a dark place at laboratory conditions. The filtered extracts were then evaporated under the laminar flow hood in a dark environment. In the third step, the residue was processed similarly with the same amount of water: methanol $(1: 1 v / v)$ for the same period and conditions and the extracts were kept dry in sealed Eppendorf tubes with aluminum sheets cover and stored in a refrigerator at $4{ }^{\circ} \mathrm{C}$ prior to chemical analysis. Water: methanol extracts were dried over anhydrous sodium sulfate before the GC-MS analysis.

Table 1. Identified chemical composition of $T$. baccata leaves water: methanol extract.

\begin{tabular}{|c|c|c|c|}
\hline$t_{\mathrm{r}}^{*}(\mathrm{~min})$ & Compound & Class & WM-LE** $(\%)$ \\
\hline 6.367 & Thymine & Phenolic compound & 1.48 \\
\hline 7.519 & 4H-pyran-4-one, 2,3-dihydro-3,5-dihydroxy-6-methyl- & Flavonoid & 2.83 \\
\hline 9.164 & 2,3-dihydrobenzofuran & Coumaran & 1.93 \\
\hline 9.366 & 2-furancarboxaldehyde, 5-(hydroxymethyl)- & n-Aldehyde & 1.29 \\
\hline 10.783 & Phenol, 4-ethenyl-2-methoxy- & Phenolic compound & 0.89 \\
\hline 13.294 & 2-propenoic acid, 3-phenyl-, (E)- & Fatty acid & 2.07 \\
\hline 13.470 & p-Propylguaiacol & Monoterpene & 0.50 \\
\hline 13.854 & 3,5-dimethoxyphenol & Taxane & 7.65 \\
\hline 15.094 & Acetic acid, (p-hydroxyphenyl)- & Fatty alcohol & 9.67 \\
\hline 16.692 & 3-(2-azidobenzyl)pyridine & Alkaloeid & 2.76 \\
\hline 17.907 & Benzeneacetic acid, 4-hydroxy-3-methoxy-, methyl ester & Fatty acid ester & 1.62 \\
\hline 18.130 & $\begin{array}{c}\text { 1,7-dimethyl-4,4a,5,6-tetrahydropyrido-1H-[1,2- } \\
\text { b]pyridazin-2(3H)-one }\end{array}$ & Others & 2.09 \\
\hline 18.955 & Pluchidiol & Others & 5.05 \\
\hline 20.750 & 1,3-dioxane, 2-(2-bromoethyl)- & Ether & 2.96 \\
\hline 21.326 & Palmitinic acid & Fatty acid & 1.80 \\
\hline 21.762 & 2-methyl-1-thia-cyclopentane & n-Alkane & 8.87 \\
\hline 23.744 & Oleic acid & Fatty acid & 20.87 \\
\hline 23.988 & Octadecanoic acid & Fatty acid & 1.34 \\
\hline 26.328 & Fusaric acid & Aromatic carboxylic acid & 1.39 \\
\hline 29.908 & Octadeca-9,12-dien-1-ol & Fatty alcohol & 17.77 \\
\hline 31.252 & 3-phenyl-1,4(E)-dodecadiene & Others & 0.60 \\
\hline 33.929 & Cholest-5-en-3-ol (3.beta.)- & Steroid & 1.71 \\
\hline
\end{tabular}

\subsection{GC-MS Analysis}

The GC-MS analysis of the resulting extracts was performed using a GC Agilent 7890A and MS Agilent 5975C mass spectrometer detector (Palo Alto, CA, USA) equipped with a HP-5MS cross-linked capillary column (30-m-long and $0.25-\mathrm{mm}$ internal diameter, $0.25 \mu \mathrm{m}$ film thickness). Helium was used as the carrier gas with a flow rate of $1 \mathrm{~mL} / \mathrm{min}$. The run time duration was $48.43 \mathrm{~min}$. The program began at $60^{\circ} \mathrm{C}$ for $2 \mathrm{~min}$ and the temperature increased at a rate of $7^{\circ} \mathrm{C} / \mathrm{min}$ up to $280^{\circ} \mathrm{C}$. It remained at this temperature for $15 \mathrm{~min}$. The intrinsic energy that hits the sample in the MS system was $70 \mathrm{eV}$. The split ratio of the sample was $2: 1$ with a split flow of $2 \mathrm{~mL} / \mathrm{min}$. The individual compounds in the extracts were identified by their retention time relative to known compounds and further identified by comparison of their mass spectra with either the known compounds or published spectral data. Individual components were identified using Wiley $275 \mathrm{~L}$ and NIST05 a.L database matching, and by comparing the retention times and mass spectra of constituents with published data [13-15].

\section{Results and Discussion \\ 3.1 Leaves and Male Cones Extracts}

The number and percentage of the total compounds in the leaves and male cones water: methanol extracts which were identified using GC-MS analysis, were 22 and $97.14 \%$ (Table 1), and 17 and $99.29 \%$, respectively (Table 2). 
Table 2. Identified chemical composition of T. baccata male cones water: methanol extract.

\begin{tabular}{cccc}
\hline $\boldsymbol{t}_{\boldsymbol{r}} \boldsymbol{*}(\mathbf{m i n})$ & Compound & Class & WM-MCE* $(\boldsymbol{\%})$ \\
\hline 6.336 & Glycerol & Alcoholic sugar & 0.48 \\
9.195 & 2,3-dihydrobenzofuran & Coumaran & 1.88 \\
9.895 & 1,2-Benzenediol, 3-methoxy- & Phenolic compound & 1.17 \\
15.131 & 3-Hydroxyphenylacetic acid & Fatty acid & 0.69 \\
16.703 & Methyl-(2-hydroxy-3-ethoxy-benzyl)ether & Ether & 0.61 \\
18.145 & Mome inositol & Sugar & 0.66 \\
18.929 & 2-ethylthiolane & Tioalkaloeid & 0.43 \\
19.318 & Propyl isopropyl ether & Aromatic ether & 0.41 \\
20.044 & 3,5-Heptadienal, 2-ethylidene-6-methyl- & n-Aldehyde & 2.66 \\
22.447 & 3-O-methyl-d-glucose & Sugar & 64.00 \\
23.723 & Oleic acid & Fatty acid & 13.32 \\
23.982 & Stearic acid & Fatty acid & 0.77 \\
27.028 & Methyl petroselinate & Fatty acid ester & 0.75 \\
27.983 & Hexadecanoic acid, 2,3-dihydroxypropyl ester & Fatty acid ester & 0.64 \\
29.908 & 9,12-Octadecadien-1-ol & Fatty alcohol & 7.70 \\
33.929 & Cholest-5-en-3-ol (3.beta.)- & Steroid & 1.10 \\
36.259 & Stigmasterol, 22,23-dihydro- & Steroid & 0.73 \\
\hline${ }^{*}:$ Retention time; **WM-MCE: Water: methanol male cones extract. & &
\end{tabular}

Table 3. Classification of the identified chemical components of the T. baccata leaves and male cones water: methanol extract.

\begin{tabular}{ccccc}
\hline No. & Chemical classes & WM-LE* $(\%)$ & WM-MCE $^{* *}(\mathbf{\%})$ & Sum (\%) \\
\hline 1 & Sugars & 0.00 & 65.14 & 65.14 \\
2 & Acids & 37.14 & 14.78 & 51.92 \\
3 & Alcohols & 17.77 & 7.70 & 25.47 \\
4 & n-Alkanes & 8.87 & 0.00 & 8.87 \\
5 & Taxanes & 7.65 & 0.00 & 7.65 \\
6 & Ethers & 2.96 & 2.19 & 5.15 \\
7 & Flavonoids & 2.83 & 1.29 & 4.12 \\
8 & n-Aldehydes & 1.29 & 2.66 & 3.95 \\
9 & Coumarans & 1.93 & 1.88 & 3.81 \\
10 & Steroids & 1.71 & 1.83 & 3.54 \\
11 & Alkaloids & 2.76 & 0.43 & 3.19 \\
12 & Esters & 1.62 & 1.39 & 3.01 \\
13 & Phenols & 2.37 & 0.00 & 2.37 \\
14 & Terpenes & 0.50 & 0.00 & 0.50 \\
15 & Others & 7.74 & 0.00 & 7.74 \\
- & Total identified & $\mathbf{9 7 . 1 4}$ & $\mathbf{9 9 . 2 9}$ & - \\
\hline
\end{tabular}

* WM-LE: Water: methanol leaves extract; **WM-MCE: Water: methanol male cones extract.

Through analyzing the qualitative characteristics of flavonoids in yew female cones (seed cones), the researchers showed that there were several flavonoids in methanol extract and the highest concentration of flavonoids $(39.37 \mathrm{mg} / \mathrm{g})$ was measured in ethyl acetate extract of seed cones [16]. Compared to the values obtained in leaves extract, seed cones extract had a lower concentration of flavonoids. The results of the data and identified compounds of our studies showed that the compounds 4H-pyran-4-one, 2,3-dihydro-3,5dihydroxy-6-methyl- (called DDMP) as only flavonoids [17] accounts for only $2.83 \%$ in the water: methanol extracts of yew leaves. The identified DDMP is an antitumor compound. Moreover, it possesses anti-microbial, anti-oxidant, anti-inflammatory, and anti-mutagenic characteristics [17]. The highest extraction percentage was 3-O-methyl-d-glucose by $64.00 \%$ and extracted from the male cones using water: methanol. 3-Omethyl-d-glucose is a nonmetabolizable chemical analog of glucose. Because of its metabolic stability, the early studies investigated the 3-O-methyl-d-glucose as a cellular transport, blood-brain barrier, and tissue apportionment expanse of hexoses [18]. In the more recent researches, 3-O-methyl-d-glucose have been used in cancer identification and track down [19]. Fusaric acid also known as 5-butylpicolinic acid extracted from the leaves using water: methanol as much as $1.39 \%$. Fusaric acid has been known as a wilting agent and also proposed for various therapeutic applications such as quorum sensing inhibitors [20]. Fusaric acid is a 
mycotoxin and has negative effects on mammals and also it prevents dopamine beta-hydroxylase enzyme. On the other hand, fusaric acid can prevent cell proliferation and DNA synthesis. However, it is primarily used in research and laboratories.

2-furancarboxaldehyde, 5-(hydroxymethyl)- which is a member of the class of furans, obtained from the leaves by water: methanol at $1.29 \%$. 2-furancarboxaldehyde, 5(hydroxymethyl)- does not exist in the fresh food, and it is naturally produced (through Millard reaction) from the processing (cooking, drying, or storing) of foods containing sugar. It is used as an index of heat treatment and deterioration in food and products such as tomato paste, honey, and fruit juices [21]. 2furancarboxaldehyde, 5-(hydroxymethyl)- also has shown hepatoprotective effects on acute alcoholinduced liver oxidative injury in mice [22]. Additionally, 2-furancarboxaldehyde, 5(hydroxymethyl)- possesses antioxidant properties and prevents the sickling of red blood cells [23-25]. In the yew male cones and leaves, oleic acid was the only fatty acid component which could be extracted using water: methanol (Tables 1 and 2). In this experiment, 2,3dihydrobenzofuran, also known as coumaran, was identified in both leaves $(1.93 \%)$ and male cones (1.88\%) using water: methanol. 2,3-dihydrobenzofuran has shown effective results against cancer, tuberculosis, malaria, and cataracts [26]. Moreover, some plant species that are reach in 2,3-dihydrobenzofuran possess antioxidant and/or cytoprotective characteristics and insecticidal features [27, 28]. Some of the common uses of oleic acid are in the food, pharmaceutical, cosmetic, and biodiesel industries [29]. Recently, oleic acid has attracted attention due to its positive effect on human disease such as blood pressure [30].

\section{Conclusion}

In this study, the chemical composition of leaves and male cones extracts of Taxus baccata L. were sequentially extracted by water: methanol and then analyzed using the GC-MS technique. In total, identified components are classified as sugars, acids, alcohols, n-alkanes, taxanes, ethers, flavonoids, naldehydes, coumarans, steroids, alkaloids, esters, phenolic compounds, terpenes, etc. There were many valuable phytocomponents that are potential bioresources for phytopharmaceutics such as 3-Omethyl-d-glucose, 4H-pyran-4-one, 2,3-dihydro-3,5dihydroxy-6-methyl-, thymine, 2,3-dihydrobenzofuran, oleic acid, and glycerol. Alcohols were identified with almost high percentages in this experiment, the total extraction of alcohols from leaves was $17.77 \%$ and from male cones was $7.70 \%$. The other compounds with high extraction percentage were acids, their total extraction using water: methanol solvent from leaves and male cones extracts were $37.14 \%$ and $14.78 \%$, respectively. Furthermore, taxanes were extracted as much as $7.65 \%$ from leaves extract, while their extraction from male cones extract was $0.00 \%$. Also, the sugar component there was not in the leaves extract by water: methanol extract, while total sugar identification from male cones reached at $65.14 \%$.

\section{Acknowledgement}

The authors are grateful for the support of the Department of Wood Science and Paper Technology, Karaj Branch, Islamic Azad University, Karaj, Iran.

\section{Author's Contributions}

Younes Shirmohammadli: Developed and performed the experiments and drafted the manuscript.

Seyyed Khalil Hosseinihashemi: Conceived of the presented experiment and supervised the findings of this work.

Abbas Jalaligoldeh: Verified the analytical methods. Davood Efhamisisi: Aided in interpretation of the results and consulted in technical details.

Seyed Hashem Mousavinezhad: Assisted with laboratory experiments.

Amir Lashgari: Assisted in sourcing materials and planning of the laboratory experiments.

\section{Ethics}

There are no ethical issues after the publication of this manuscript.

\section{References}

1. Jovanović, B. Taxus L. In: Josifović M (ed) Flora of Serbia 1, SASA, Belgrade, 1970, pp 164-166.

2. Efhamisisi, D.; Topa, A. The effect of xylem extractives on natural durability of yew wood against different rotting fungi. Journal of Forest and Wood Products, 2018, 71(1), 49-59.

3. Afraz, S.; Hosseinihashemi, S. K. Extraction and identification of chemical compounds in acetone extract of Taxus baccata L. bark. Iranian Journal of Wood and Paper Science Research, 2018, 33(1), 88-99.

4. Vencurik, J.; Bosela, M.; Sedmáková, D.; Pittner, J.; Kucbel, S.; Jaloviar, P.; Saniga, M. Tree species diversity facilitates conservation efforts of European yew. Biodiversity and Conservation, 2019, 28(4), 791-810.

5. Todorov, T.; Stamberov, P.; Nikolov, B.; Manova, G.; Manov, V. Fatal European yew (Taxus baccata) poisoning in two horses. Tradition Mod Veterinary Medicine, 2019, 4(2(7)), 34-39.

6. Osuna-Torres, L.; García-Martí, X.; Ventura-Zapata, E.; LópezUpton, J.; Zamilpa-Alvarez, A.; González-Cortázar, M.; TapiaBarrera, N. Taxus globosa Schltdl. (Mexican yew) and Taxus baccata L. (European yew): intra and interspecies analysis of taxol content and biological activity according to different sources. Forest Systems, 2015, 24(3), 045.

7. Dziadosz, M.; Lessig, R.; Bartels, H. A way of handling Taxus baccata intoxications in forensic laboratories. Egyptian Journal of Forestry Sciences, 2014, 4(2), 50-53. 
8. Perju-Dumbravă1, D.; Morar, S.; Chiroban, O.; Lechintan, E.; Cioca, A. Suicidal poisoning by ingestion of Taxus Baccata leaves. Case report and literature review. Romanian Journal of Legal Medicine, 2013, 21, 115-118.

9. Sarli, S.; Ghasemi, N. Optimization of biosynthesized $\mathrm{Zn}$ nanoparticles by poisonous Taxus baccata leaves extract and evaluation of their effect on the bacterias and MCF-7 cancer cells. Eurasian Chemical Communication, 2020, 2(3), 302-318.

10. Sadeghi-Aliabadi, H.; Asghari, G.; Mostafavi, S. A.; Esmaeili, A. Solvent optimization on Taxol extraction from Taxus baccata $\mathrm{L}$. using HPLC and LC-MS. DARU Journal of Pharmaceutical Science, 2015, 17(3), 192-198.

11. Yasar, S. Volatile constituents of Taxus baccata L. leaves from western and southern Turkey. Asian Journal of Chemistry, 2013 25(16), 9123-9125.

12. Glowniak, K.; Mroczek, T.; Zobel, A. M. Seasonal changes in the concentrations of four taxoids in Taxus baccata L. during the autumn-spring period. Phytomedicine, 1999, 6(2),135-140.

13. Julain, D.; König, W. A. The Atlas of Spectral Data of Sesquiterpene Hydrocarbons; E. B. Verlag, Hamburg univ. Press: E. B. Verlag, Hamburg, Germany, 1988; pp 661

14. Adams, R. P. Identification of Essential oil Components by Gas Chromatography/Mass Spectrometry; 1st edn. Allured Publishing Corp., Carol Stream, IL, 60188, USA, 1995; pp 469.

15. Adams, R. P. Identification of Essential Oil Components by Gas Chromatography/Quadrupole Mass Spectroscopy; 3rd edn. Allured Publishing Corp., Carol Stream, IL, 60188, USA, 2001; pp 469.

16. Milutinović, M. G.; Stanković, M. S.; Cvetković, D. M.; Topuzović, M. D.; Mihailović, V. B.; Marković, S. D. Antioxidant and anticancer properties of leaves and seed cones from European yew (Taxus baccata L.). Archives of Biologicsl Sciences, 2015, 67(2), 525-534.

17. Teoh, Y. P.; Mashitah, M. D. Screening of antifungal activities from genera Trametes against growth of selected wood-degrading fungi from Malaysia. Australian Journal of Basic \& Applied Sciences, 2012, 6(1), 79-85.

18. Jay, T. M.; Dienel, G. A.; Cruz, N. F.; Mori, K.; Nelson, T. Sokoloff, L. Metabolic stability of 3-O-methyl-d-glucose in brain and other tissues. Journal of Neurochemistry, 1990, 55(3), 9891000 .

19. Sehgal, A. A.; Li, Y.; Lal, B.; Yadav, N. N.; Xu, X.; Xu, J.; Laterra, J.; van Zijl, P. C. M. CEST MRI of 3-O-methyl-glucose uptake and accumulation in brain tumors. Magnetic Resonance in Medicine, 2018, 81(3), 1993-2000.

20. Tung, T. T.; Jakobsen, T. H.; Dao, T. T.; Fuglsang, A. T.; Givskov, M.; Christensen, S. B.; Nielsen, J. Fusaric acid and analogues as gram-negative bacterial quorum sensing inhibitors. European Journal of Medicinal Chemistry, 2017, 126, 1011-1020.

21. Arena, E.; Fallico, B.; Maccarone, E. Thermal damage in blood orange juice: kinetics of 5-hydroxymethyl-2-furancarboxaldehyde formation. International Journal of Food Science and Technology, 2001, 36(2), 145-151.

22. Li, W.; Qu, X.-N.; Han, Y.; Zheng, S.-W.; Wang, J.; Wang, Y.-P. Ameliorative effects of 5-hydroxymethyl-2-furfural (5-HMF) from schisandrachinensis on alcoholic liver oxidative injury in mice. International Journal of Molecular Sciences, 2015, 16(2), 2446-2457.
23. Janzowski, C.; Glaab, V.; Samimi, E.; Schlatter, J.; Eisenbrand, G. 5-hydroxymethylfurfural: Assessment of mutagenicity, DNAdamaging potential and reactivity towards cellular glutathione. Food and Chemical Toxicology, 2000, 38(9), 801-809.

24. Li, M. M.; Wu, L. Y.; Zhao, T.; Xiong, L.; Huang, X.; Liu, Z. H.; Fan, X. L.; Xiao, C. R.; Gao, Y.; Ma, Y. B.; Chen, J.; Zhu, L. L. The protective role of 5-HMF against hypoxic injury. Cell Stress and Chaperones, 2011, 16(3), 267-273.

25. Zhao, L.; Chen, J.; Su, J.; Li, L.; Hu, S.; Li, B.; Zhang, X.; Xu, Z.; Chen, T. In vitro antioxidant and antiproliferative activities of 5 hydroxymethylfurfural. Journal of Agricultural and Food Chemistry, 2013, 61(44), 10604-10611.

26. Sheppard, T. D. Strategies for the synthesis of 2, 3dihydrobenzofurans. Journal of Chemical Research, 2011, 35(7), 377-385.

27. Chin, Y. W.; Chai, H. B.; Keller, W. J.; Kinghorn, A. D. Lignans and other constituents of the fruits of Euterpeoleracea (Acai) with antioxidant and cytoprotective activities. Journal of Agricultural and Food Chemistry, 2008, 56(17), 7759-7764.

28. Huang, Z.; Cui, Q.; Xiong, L.; Wang, Z.; Wang, K.; Zhao, Q.; Wang, Q. Synthesis and insecticidal activities and SAR studies of novel benzoheterocyclicdiacylhydrazine derivatives. Journal of Agricultural and Food Chemistry, 2009, 57(6), 2447-2456.

29. Whelan, L. Oleic acid: Production, Uses and Potential Health Effects, Published by Nova Science Publishers, Inc., UK; 2014, pp 139.

30. Ruiz-Gutierrez, V.; Muriana, F. J.; Guerrero, A.; Cert, A. M.; Villar, J. Plasma lipids, erythrocyte membrane lipids and blood pressure of hypertensive women after ingestion of dietary oleic acid from two different sources. Journal of Hypertension, 1996, 14(12), 1483-1490. 